\title{
Lung fibrosis in autoimmune diseases and hypersensitivity: how to separate these from idiopathic pulmonary fibrosis
}

\author{
Helmut Popper ${ }^{1}\left[\right.$ E Elvira Stacher-Priehse ${ }^{2} \cdot$ Luka Brcic $^{1} \cdot$ Andreas Nerlich $^{3}$
}

Received: 23 July 2021 / Accepted: 15 September 2021 / Published online: 4 October 2021

(c) The Author(s) 2021

\begin{abstract}
Lung involvement in autoimmune diseases (AID) is uncommon, but may precede other organ manifestations. A diagnostic problem is chronicity presenting with lung fibrosis. A new category of interstitial pneumonia with autoimmune features for patients with clinical symptoms of AID and presenting with usual interstitial pneumonia (UIP) enables antifibrotic treatment for these patients. Hypersensitivity pneumonia (HP) and other forms of lung fibrosis were not included into this category. As these diseases based on adverse immune reactions often present with unspecific clinical symptoms, a specified pathological diagnosis will assist the clinical evaluation. We aimed to establish etiology-relevant differences of patterns associated with AID or HP combined with lung fibrosis. We retrospectively evaluated 51 cases of AID, and 29 cases of HP with lung fibrosis, and compared these to 24 cases of idiopathic pulmonary fibrosis (UIP/IPF). Subacute AID and HP most often presented with organizing pneumonia (OP), whereas chronicity was associated with UIP. Unspecified fibrosis was seen in a few cases, whereas NSIP pattern was rare. In 9 cases, the underlying etiology could not be defined. Statistically significant features differentiating chronic AID or HP from UIP/IPF are lymphocytic infiltrations into myofibroblastic/fibroblastic foci. Other features significantly associated with AID and HP were granulomas, isolated Langhans giant cells, and protein deposits, but seen in only a minority of cases. A combination of UIP with one of these features enabled a specific etiology-based diagnosis. Besides the antifibrotic drug regimen, additional therapies might be considered.
\end{abstract}

Keywords Fibrosing pneumonia $\cdot$ Chronic autoimmune disease $\cdot$ Rheumatoid arthritis $\cdot$ Systemic sclerosis $\cdot$ Sjøgren syndrome $\cdot$ Systemic lupus $\cdot$ Chronic hypersensitivity pneumonia $\cdot$ UIP · IPF

\section{Introduction}

Autoimmune diseases (AID) are heterogenous, some of them affecting joints, others involving blood vessels, but all can involve the lung [1-3]. They all have in common deregulation of the immune system resulting in auto-aggression against normal tissues [4-8]. In some diseases, a clinical diagnosis is usually straightforward as patients present with a typical clinical picture, e.g., skin affection and glomerular disease in systemic lupus erythematosus (systemic

Helmut Popper

Helmut.popper@medunigraz.at

1 Medical University Graz, Diagnostic and Research Institute of Pathology, Neue Stiftingtalstr. 6, 8036 Graz, Austria

2 Institute of Pathology, Asklepios-Fachkliniken Gauting, Gauting, Germany

3 Department of Pathology, Teaching Hospital Munich-Bogenhausen, Munich, Germany lupus), or joint inflammation in rheumatoid arthritis. Most of these AIDs can affect the lung. In a minority of cases, lung involvement can precede the classical symptoms delaying or impeding the diagnosis [9]. This can result in undetected and untreated pulmonary disease, which might progress into fibrosis. Diagnosis of hypersensitivity pneumonia (HP) is straightforward in the acute stage by an exposure anamnesis, typical undulating symptoms associated with allergen exposure, and morphologically by loose peripherally concentrated epithelioid cell granulomas combined with lymphocytic interstitial pneumonia (LIP), dominated by $\mathrm{CD} 8^{+}$ $\mathrm{T}$ cells. Due to the increased sensitivity of CT scans and awareness of fibrosing pneumonia, more biopsies are performed, resulting in an increase of AID and HP with lung fibrosis.

Three classic patterns are recorded in AID and HP with pulmonary fibrosis: usual interstitial pneumonia (UIP), nonspecific interstitial pneumonia (NSIP), and organizing pneumonia (OP). Unspecified fibrosis of the lung is rarely seen 
$[1,10-15]$. UIP is also the pattern of idiopathic pulmonary fibrosis (IPF). A sequence of morphologic events is seen in UIP, starting with apoptosis of pneumocytes, followed by a repair by myofibroblasts, and regeneration of the epithelial layer, during which some epithelial cells differentiate into senescent cells [16-19]. Inflammatory cells will be absent or only be seen in cystic remodeled areas due to bacterial colonization. Senescent cells release inflammatory cytokines, stimulate the proliferation of myofibroblasts, and prolong the repair process, resulting in fibrosis. Different molecular abnormalities have been found in IPF as well as in UIPassociated AIDs, e.g., premature aging of pneumocytes due to mutations of telomere maintenance genes [20-22], mutations of surfactant apoprotein genes [23-25], contributing to prolonged inflammation, and promoter mutation in MUC5B $[26,27]$, which might reduce mucociliary clearance and disrupt regeneration [28].

As AID and HP associated with UIP clinically often cannot be attributed to a specific AID, the term interstitial pneumonia with autoimmune features (IPAF) has been created [29]. This term encompasses active and inactive AID with anti-nuclear antibodies but excludes HP. Morphologically different types of fibrosing pneumonia are included [30]. If UIP in IPF can be differentiated from UIP in AID and fibrosing HP has rarely been evaluated but might be of prognostic relevance [1, 12, 14, 31-34]]. Some publications showed that lymphoid hyperplasia is associated with systemic sclerosis, dermatomyositis/polyserositis, and rheumatoid arthritis. They also reported a different anatomical distribution for each of these AIDs and mentioned rheumatoid nodules as a distinctive feature for rheumatoid arthritis [34, 35].

Reports on survival of AID or HP with UIP pattern are divergent [14, 31, 33, 36-38]. Similar to IPF, both diseases progress stepwise. Here, we aimed to analyze the different patterns of AID and fibrosing HP in a retrospective series and compare this to IPF to identify features, which might allow an etiology-based diagnosis. We believe a more detailed pathological report over just a UIP pattern report will help in a better stratification of patients and concise discussion within the multidisciplinary team [39]. Additional therapies to the established antifibrotic treatment protocol might be considered.

\section{Materials and methods}

From the lung tissue archive of the Institute of Pathology, Medical University of Graz, 113 cases were selected when any kind of lung fibrosis was present, and the initial clinical diagnosis and a clinical follow-up were available. We did not include end-stage diseases, such as seen in explant lung tissue, because a specific diagnosis often is not possible in these tissues.
There were 51 cases of clinically active AID, 29 cases of HP, and 24 clinically confirmed IPF cases based on the presence of UIP pattern. In seven cases, the final diagnosis was either AID or HP. In two cases, a final diagnosis of either IPF or AID could not be reached. In all these cases, a clinical diagnosis and clinical response to the pathological report was received either submitted with the tissue or after the pathological report was issued. Most cases were submitted for consultation. Fibrosis was seen in the form of UIP, fibrosing NSIP, OP, unspecific fibrosis, and airway-centered interstitial fibrosis (ACIF) (Suppl. Table 1).

\section{Definition of patterns is given in Suppl. Table 2}

In UIP, we use the term myofibroblastic foci instead of fibroblastic focus because these cells are essentially myofibroblasts expressing myogenic markers; also, honeycombing is replaced by cystic remodeling, which can be seen in primary lobules, whereas radiologists by honeycombing describe cystic changes in secondary lung lobules. In ACIF, fibrosis extends from small airways to the periphery, combined with muscular hyperplasia and metaplasia of bronchial epithelia [40]. In contrast to NSIP, LIP is characterized by diffuse monomorphic infiltration of lymphocytes and plasma cells, with few scattered immunoblasts, with or without follicular hyperplasia of BALT (bronchus-associated lymphoid tissue), whereas in cellular NSIP histiocytes and macrophages combine with lymphocytes. Scattered and focal infiltrations of lymphocytes were not regarded as LIP but were described. Other features of AID and HP are histiocytic or epithelioid cell granulomas, amyloid or immune complex deposition with/without complement activation, isolated BALT hyperplasia, lymphocytic bronchitis/bronchiolitis, follicular bronchiolitis, peribronchial fibrosis (constrictive bronchiolitis), and hemorrhage-often mixed in different proportions. Amyloid was defined by a positive Congo red stain with green birefringence and by immunohistochemistry for amyloid A, or P. Immune complex deposition was verified by a positive immunohistochemical reaction for IGG and concomitant activation of complement 1q, 3c, and 5-9 complex in formalin-fixed and paraffin-embedded tissues.

The tissues were obtained by video-assisted thoracoscopy (open lung biopsy) or bronchoscopy-derived cryobiopsies. Hematoxylin and Eosin (H\&E)-stained slides were available in all cases. In cases where a differential diagnosis of AID or HP was raised, immunohistochemistry for lymphocyte subtypes was performed, using antibodies for CD3, CD4, $\mathrm{CD} 8, \mathrm{CD} 20$, rarely for FOXP3, characterizing regulatory $\mathrm{T}$ cells. All cases were re-evaluated by HP and ES. The presence or absence of the following patterns was recorded for each case: myofibroblastic foci, cystic remodeling of lung lobules, spatial and temporal heterogeneity, fibrosis, lymphocytes infiltrating the myofibroblastic foci, hyperplasia 
Table 1 Features, which are helpful for the differentiation of autoimmune disease and fibrosing hypersensitivity pneumonia from idiopathic pulmonary fibrosis (presence of feature/pattern $=1$, absence $=0$ ); * denotes which of the entities are statistically compared

\begin{tabular}{|c|c|c|c|c|}
\hline Features & AID & HP & IPF & Significance \\
\hline Lymphocytes in myofibroblastic foci & $\begin{array}{l}\text { Yes*(1) } \\
0.91 \pm 0.28\end{array}$ & Yes (1) & $\begin{array}{l}\text { No* }(0) \\
0.16 \pm 0.38\end{array}$ & $* p<0.0001$, AID vs IPF \\
\hline Lymphocytes in myofibroblastic foci & Yes* (1) & Yes* (1) & & $* p=0.92$, AID vs HP \\
\hline Granulomas or giant cells & Yes* (1) & Yes (1) & $\mathrm{No}^{*}(0)$ & $* p=0.028$, AID vs IPF \\
\hline Granulomas or giant cells & $\begin{array}{l}\text { Yes* }^{*}(1) \\
0.66 \pm 0.47\end{array}$ & $\begin{array}{l}\text { Yes* (1) } \\
0.28 \pm 0.45\end{array}$ & & $*_{p} p<0.001$, HP vs AID \\
\hline Hyperplasia of BALT & $\begin{array}{l}\text { Yes* } \\
0.48 \pm 0.50\end{array}$ & $\begin{array}{l}\text { Yes** } \\
0.32 \pm 0.47\end{array}$ & $\begin{array}{l}\text { No* } \\
0.0\end{array}$ & $\begin{array}{l}* \text { AID vs IPF } p=0.001 \\
* * \text { HP vs IPF } p=0.023 \\
\text { AID vs HP } p=0.09\end{array}$ \\
\hline Amyloid or immune complex deposition & Yes* & No* & No & $*$ AID vs HP $p=0.004$ \\
\hline Predominance of CD8 lymphocytes & No & Yes & No & \\
\hline Mixed lymphocytic infiltrations (CD4, CD8, CD20) & Yes & No & No & \\
\hline Chronic pleuritis \pm fibrin exudate if present & Yes & No & No & \\
\hline
\end{tabular}

of BALT, histiocytic and/or epithelioid granulomas, isolated Langhans giant cells, amyloid or immune complex deposition, complement activation, vasculitis, hemorrhage, vasculopathy (myxoid changes of the intima with few scattered lymphocytes), vascular sclerosis, neutrophils, eosinophils. Additional features not generally associated with fibrosing pneumonias were also recorded (e.g., chronic bronchitis/ bronchiolitis and pleuritis, peribronchial fibrosis).

For statistical analysis, cases were separated into AID, HP, and IPF. The program Kaleidagraph (Synergy Software, v4.5) was used. A significance was stated if the $p$ value was $\leq 0.05$.

\section{Results}

\section{Study cohort}

There were altogether 51 cases with active AID, 29 cases of HP with fibrosis, and 24 confirmed UIP/IPF cases. 9 cases
Fig. 1 Systemic sclerosis illustrated; a UIP pattern was present with myofibroblastic foci (single arrows) and remodeling $(\mathbf{A}, \mathbf{B}, \mathbf{C}, \mathbf{D})$; in $(\mathbf{B})$ the intimate association of lymphocytes with a myofibroblastic focus (single arrow) is a significant feature pointing to an immune disorder with UIP pattern. In (D), the myxoid changes of the intima (double arrow) are seen in a middle-sized pulmonary artery. H\&E, bars 100, 50, $20 \mu \mathrm{m}$
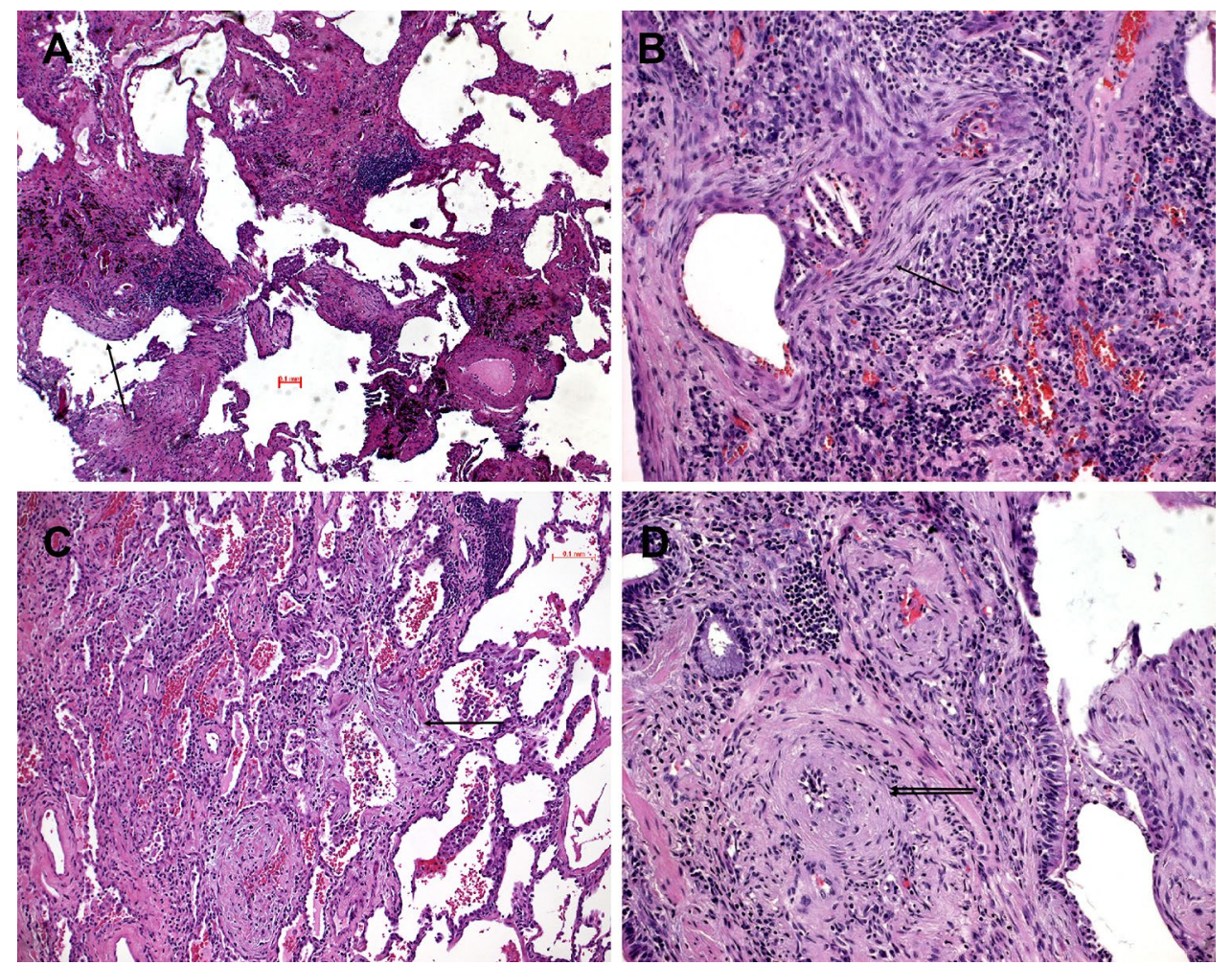


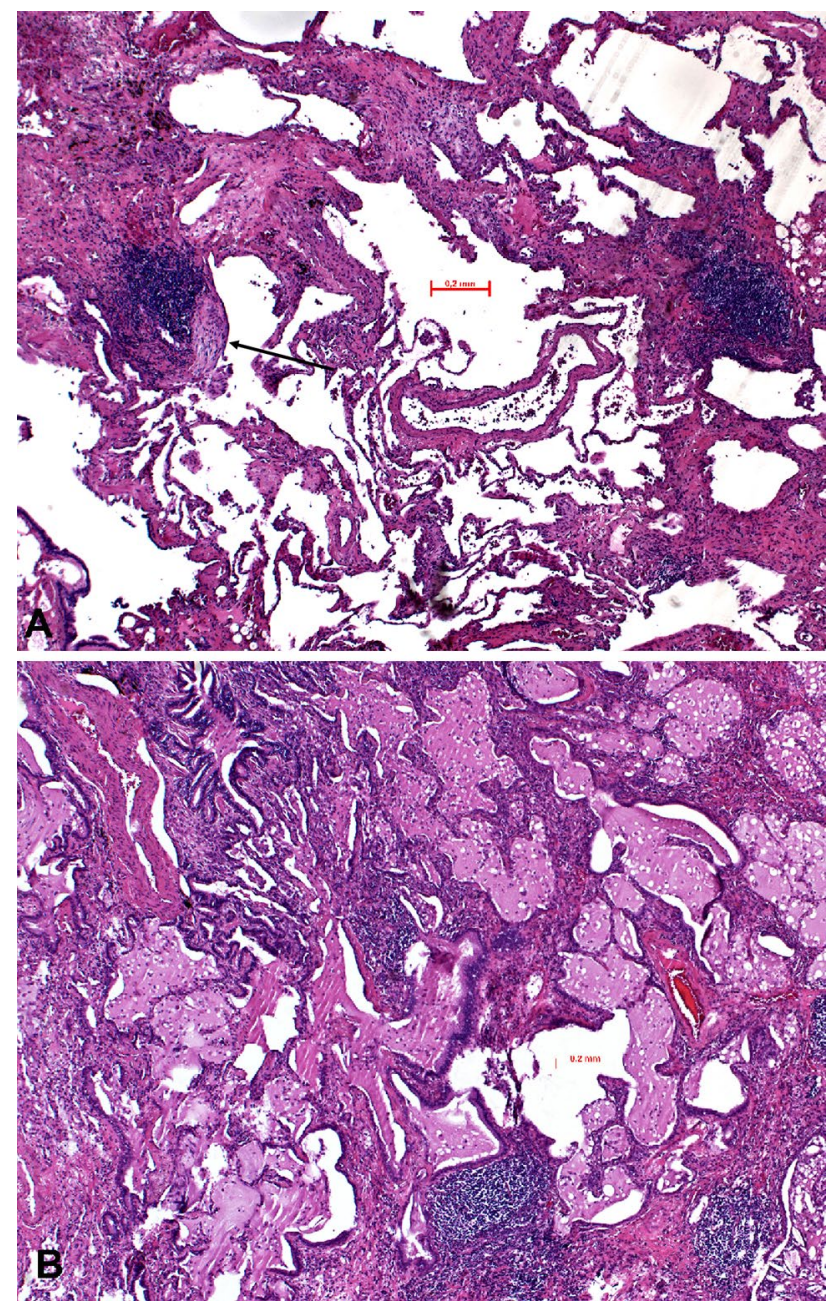

Fig. 2 Hyperplasia of the bronchus-associated lymphoid tissue in two cases of systemic sclerosis with UIP pattern. In (A) myofibroblastic foci in addition to lymph follicles associated with bronchovascular bundles are seen (arrow); in (B) cystic remodeling of lung lobules with mucostasis are seen. H\&E, bars $200 \mu \mathrm{m}$

could not be assigned into these categories (Suppl. Tables 1 and 2).

\section{Histological findings in autoimmune disease}

In 21 cases, a UIP pattern was seen, in two of them combined with OP; in 9 cases, UIP was combined with LIP pattern. In 10 cases, OP was prevalent, in 2 of them combined with LIP. In 9 cases, non-specific interstitial fibrosis was seen, in the majority combined with LIP. One case presented with fibrosing NSIP, and in one case, only BALT hyperplasia was found (Suppl. Table 3).

In 28 additional cases of AID, a more specific diagnosis could be established: rheumatoid arthritis in 10, systemic sclerosis in 10, systemic lupus in 2, Sjøgren's disease in 2 cases, and one case each for Behcet disease, dermatomyositis, Goodpasture syndrome, and one case probably associated with autoimmune liver disease.

\section{Findings in hypersensitivity pneumonia}

In 19 of 29 cases of HP, a UIP pattern was seen, combined with LIP in 12 cases. Five cases presented with OP, in four combined with LIP; 4 cases showed unspecified fibrosis, in 3 combined with LIP, ACIF was present in one case.

In 7 cases, a differential diagnosis of either AID or HP was made. (Suppl. Table 3). There were lymphocytic infiltrates within the myofibroblastic foci, however, no other additional features; for subtyping, the number of lymphocytes was too low.

\section{Findings in IPF}

All 24 cases of IPF showed the typical UIP pattern without pronounced inflammation (Table 1, Suppl.Table3). In 2 additional cases, a differential diagnosis of either AID or IPF was rendered-these were cryobiopsies with few myofibroblastic foci and scattered lymphocytes outside the myofibroblastic foci.

\section{Different patterns in AID, HP, and IPF (see Table 1 and Suppl. Table 3)}

The presence of lymphocytes infiltrating myofibroblastic foci in AID and HP (Fig. 1) was statistically significantly different from IPF ( $p<0.0001$, Table 1$)$, whereas no significant difference was seen between AID and HP $(p=0.92)$. The presence of histiocytic/epithelioid cell granulomas and/or Langhans giant cells in AID versus IPF was significantly different, as granulomas were absent in all IPF cases $(p=0.028$, Table 1); however, granulomas were present in a minority of AIDs. Granulomas or isolated Langhans cells were more often encountered in HP compared to AID, their presence favoring HP $(p<0.001)$. The presence of BALT hyperplasia (Fig. 2) favored AID as well as HP ( $p=0.001$ and $p=0.023$, respectively) when compared to IPF; no significant difference was seen between AID and HP ( $p=0.09$; Table 1). There was no deposition of amyloid or autoimmune complexes (Figs. 3, 4) in IPF and HP, which rendered this feature significant for AID ( $p=0.004$, Table 1$)$. But again, only a small number of AID cases presented with deposits. Other features such as chronic bronchitis/bronchiolitis, vasculitis, hemorrhage, and degenerative changes of the intima (vasculopathy) were seen in few cases; therefore, a statistical analysis was not performed. In contrast to other reports, we rarely encountered peribronchial or peribronchiolar fibrosis in AID and HP ( 9 and 3 cases each). 
Fig. 3 Rheumatoid arthritis with lung involvement, one case is illustrated; In A, a dense lymphoid infiltration is seen, myofibroblastic foci (arrows) are in $(\mathbf{A})$ and $(\mathbf{B})$ a loose granuloma (arrow) is shown in (C), and amyloid in (D).H\&E, bars $100,50 \mu \mathrm{m}$
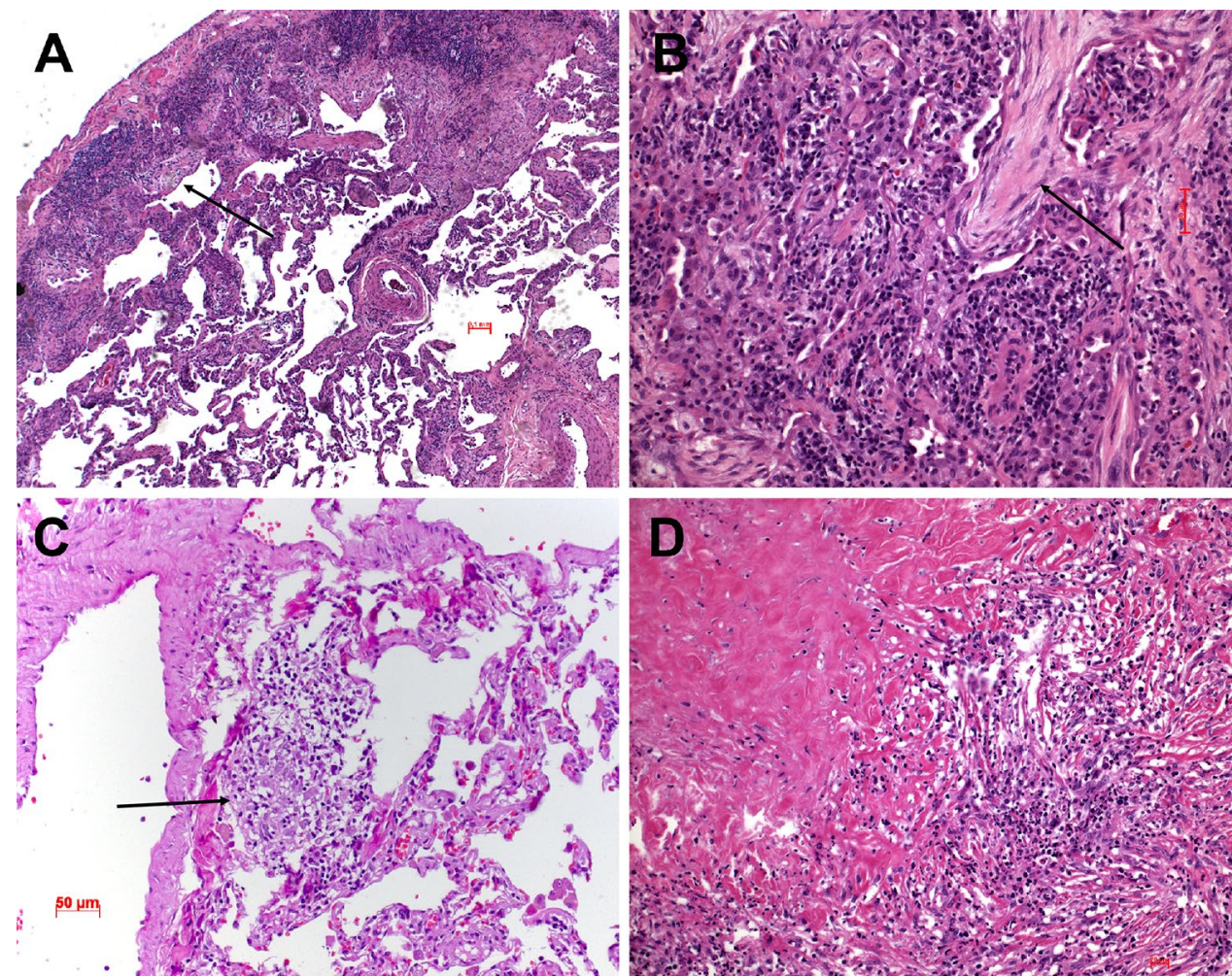

\section{Differences of AID versus HP by Immunohistochemistry}

In cases of HP and AID, where a sufficient number of lymphocytes could be evaluated, a predominance of $\mathrm{CD} 8^{+}$ lymphocytes were seen in HP, whereas in AID CD20 ${ }^{+} \mathrm{B}$ cells, $\mathrm{CD}^{+}$, and $\mathrm{CD} 8^{+} \mathrm{T}$ cells were present in different proportions; scattered $\mathrm{FOXP}^{+}$regulatory $\mathrm{T}$ cells were seen in $\mathrm{HP}$ - these were scarce in AID. Inflammatory infiltrates within the pleura always favored AID (Table 1).

In several additional AID cases, a more specific diagnosis could be suggested to the clinicians (Tables 1, 2, and 3). Examples were cases of rheumatoid arthritis presenting with combinations of UIP, LIP, granulomas, and amyloid deposits (Fig. 3). A combination of arterial thrombosis, immune complex deposits, complement activation, and hemorrhage pointed to systemic lupus (Fig. 4). A LIP pattern combined with $\mathrm{OP}$ and lymphoepithelial lesions with predominant $\mathrm{CD}^{+} \mathrm{T}$ cells favored Sjøgren's disease (Fig. 5). Finally, UIP combined with LIP, hyperplasia of BALT, and myxoid changes of the intima of pulmonary arteries were suggestive of systemic sclerosis (Fig. 1). Goodpasture disease could be suggested due to alveolar hemorrhage, fibrosis, and the proof of linear immunoglobulin deposits at the basal membrane of alveolar septa and capillaries combined with complement activation. In Behcet disease, a rheumatoid disorder was suggested because of large fibrotic areas, few ill-formed epithelioid cell granulomas, amyloid deposits, and scattered lymphocytic infiltration (Suppl. Figure 1).

\section{Discussion}

Fibrosing pneumonias are histopathologically differentiated into UIP, NSIP, and OP. International guidelines suggest not to perform biopsies when clinical and radiological features favor UIP/IPF [41]. However, new studies showed that the radiologic features of UIP are not specific enough to make a diagnosis of IPF. Wright et al. evaluated 23 cases and found that features of peribronchiolar metaplasia and giant cells or granulomas were in favor of HP and excluded IPF-features which can only be assessed in biopsies [42]. A multidisciplinary team discussion could not solve even one-third of their cases. Similarly, Churg pointed to other features favoring HP over IPF, such as upper-lobe predominance, giant cells or granulomas, and peribronchiolar metaplasia [43]. A few reports have focused on AID/connective tissue diseases, showing a fibrosing pattern very similar to IPF [34, $44,45]$. In the studies of Ito and Kim, several cases had to be reclassified from IPF into connective tissue disease. Even genetic alterations of surfactant and telomerase genes have been reported in AID similar to IPF, illustrating that these molecular alterations cannot assist in the differential diagnosis $[46,47]$. Whereas the NSIP pattern almost exclusively 

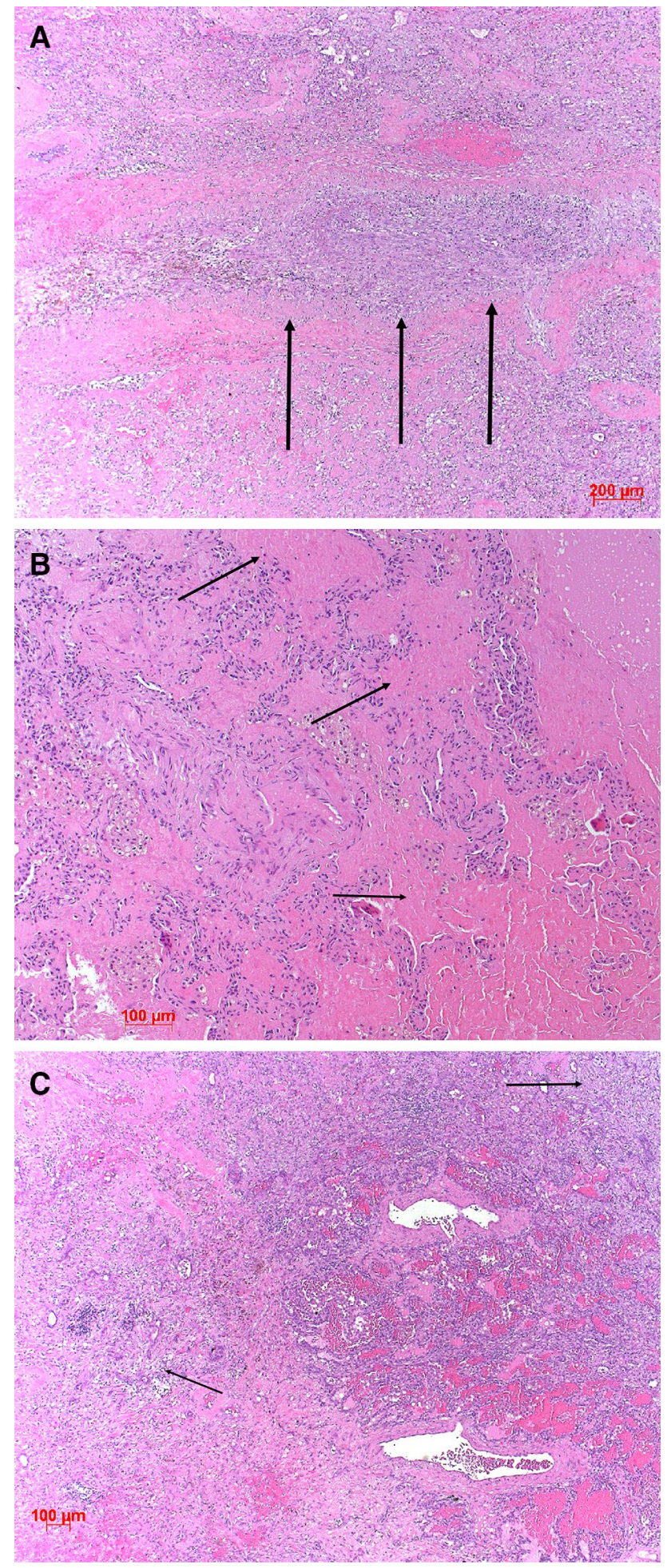

Fig. 4 SLE illustrated; A shows arterial thrombosis in an organization (arrows), eosinophilic deposits (arrows) mimicking amyloid and unspecific fibrosis is seen in (B), and fibrosis focally OP (arrows) with hemorrhage in C). H\&E, bars 200, $100 \mu \mathrm{m}$ is associated with AID or HP, the UIP pattern has a wider range of differentials. Positive anti-nuclear antibodies (ANA) are not always present in AID with lung fibrosis, and CT scans might discriminate IPF from AID only in cases with unusual distribution patterns [48]. If AID with UIP pattern has a better overall survival remains uncertain, and therefore studies separating these from IPF are warranted.

This study demonstrated that a pathological analysis of additional patterns to UIP, NSIP, or OP could provide more information about an underlying etiology. Lymphocytes infiltrating myofibroblastic foci are indicators of immune disease, either AID or HP. Other combinations of UIP with granulomas and/or giant cells, BALT hyperplasia, and protein deposits are also characteristic of immune disorders. Based on these findings, the pathological report can exclude IPF. The issued report can further strengthen the discussion in a multidisciplinary team.

Even more, due to specific patterns in some AIDs, the pathologic report can provide a preference for one of the AIDs, as shown here in roughly half of these cases (Table 1, 3). Rheumatoid arthritis with lung involvement can present with UIP or NSIP, often combined with LIP in the former. Pathognomonic histiocytic granulomas are seen especially in seropositive forms of RA. In rheumatoid arthritis, deposition of immune complexes, as well as amyloid, is common. Very large idiotypic-anti-idiotypic immune complexes with granulomatous reaction are most often encountered in rheumatoid arthritis less in systemic lupus [6, 49, 50]. Therefore, if a combination of these patterns is seen in a biopsy, rheumatoid arthritis can be suggested. In the authors' experience, systemic lupus rarely presents with UIP, but often a combination of OP, unspecific fibrosis, thrombosis, and deposition of immune complexes is seen. In systemic lupus, these antigen-antibody complexes activate complement, which can be proven by immunohistochemistry. Systemic sclerosis is known for its high numbers of autoantibodies and circulating immune complexes. In our cases, a UIP pattern with hyperplasia of BALT and myxoid changes of the pulmonary arteries with scattered intimal lymphocytes was commonly seen and did allow the suggestion for systemic sclerosis. Sjøgren's disease is characterized by an aggressive lymphocytic infiltration of the mucosa of bronchi and bronchioles, mimicking lymphoepithelial lesions. After excluding MALT lymphoma, a combination of OP and LIP with a $\mathrm{CD}^{+}$Tcell infiltration (in our cases) and lymphoepithelial lesions are suggestive for Sjøgren's disease.

Fibrosing HP can, in some instances, be differentiated from AID. Protein deposits help to rule out HP, whereas scattered giant cells and ill-formed granulomas favor HP. In contrast to other reports, we could not see any significant difference between AID and HP with respect to BALT hyperplasia [51]. NSIP was relatively rare in our cases. NSIP and an isolated OP pattern were associated preferentially with 
Table 2 Features seen in autoimmune diseases. The more morphologic features are combined, the better the diagnosis can be specified
Table 3 Combinations of features which might allow a more specific diagnosis for certain AIDs

\begin{tabular}{|c|c|c|c|c|c|c|}
\hline Patterns present & $\begin{array}{l}\text { Rheu- } \\
\text { matoid } \\
\text { arthritis }\end{array}$ & SLE & SSc & $\begin{array}{l}\text { Dermato- } \\
\text { myositis }\end{array}$ & Sjøgren & Fibrosing HP \\
\hline UIP pattern & Yes & No & Yes & Yes & No & Yes \\
\hline NSIP pattern & Yes & No & Yes & Yes & No & Yes \\
\hline OP pattern & Yes & Yes & Yes & Yes & Yes & Yes \\
\hline Unspecific Fibrosis & Yes & Yes & No & Yes & Yes & No \\
\hline Lymphocytic infiltrations or LIP & Yes & Yes & Yes & Yes & Yes & Yes \\
\hline Giant cells & Yes & No & No & Yes & No & Yes \\
\hline Lymphoid hyperplasia & Yes & No & Yes & Yes & Yes & Yes \\
\hline Epithelioid or histiocytic cell granulomas & Yes & No & No & Yes & No & Yes \\
\hline \multicolumn{7}{|l|}{ Alveolitis } \\
\hline Amyloid deposition & Yes & No & Yes & Yes & Yes & No \\
\hline Immune complex deposition & Yes & Yes & Yes & Yes & No & No \\
\hline Complement activation & Yes & Yes & No & No & $?$ & No \\
\hline \multicolumn{7}{|l|}{ Vasculitis } \\
\hline Vasculopathy & No & Yes & Yes & No & No & No \\
\hline Vascular sclerosis & No & No & Yes & No & No & No \\
\hline Alveolar hemorrhage, fresh and old & No & Yes & No & No & Yes & No \\
\hline Neutrophils & Yes & Yes & Yes & Yes & No & No \\
\hline Eosinophils & Yes/no & No & No & Yes & No & Yes \\
\hline Bronchiolitis and/or specific forms thereof & Yes & No & Yes & Yes & Yes & Yes \\
\hline LE phenomenon & No & Yes & No & No & No & No \\
\hline
\end{tabular}

The more morphologic features are combined, the better the diagnosis can be specified

\begin{tabular}{ll}
\hline Rheumatoid arthritis & UIP, LIP, granulomas, amyloid, CD4/CD8/CD20 present \\
\hline Systemic Lupus & arterial thrombosis, hemorrhage, pleuritis, immune complex deposition \\
Systemic sclerosis & UIP, LIP, hyperplasia of BALT, vasculopathy \\
$\begin{array}{l}\text { Chronic/subacute Sjøgren } \\
\begin{array}{l}\text { Behcet disease and other rheuma- } \\
\text { toid diseases }\end{array}\end{array}$ & $\begin{array}{c}\text { FIP, OP, lymphoepithelial lesions, CD8 }{ }^{+} \text {dominance } \\
\text { ill-formed granulomas }\end{array}$ \\
\hline
\end{tabular}

Fig. 5 Sjøgren's disease illustrated; in (A), organizing pneumonia (arrow) and dense lymphocytic infiltrations are seen, focally (B) showing a lymphoepithelial lesion (double arrow). H\&E, bars 100 and $20 \mu \mathrm{m}$

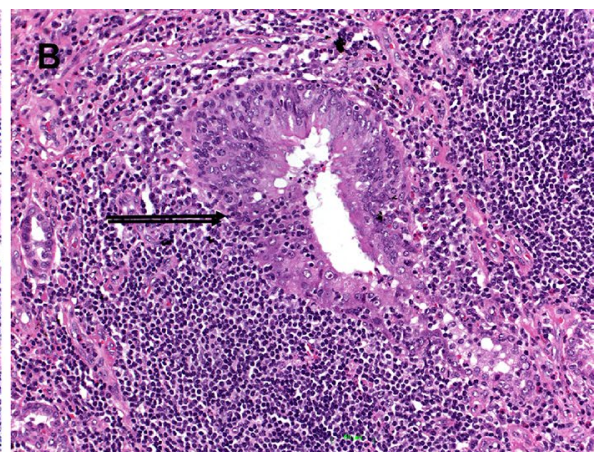

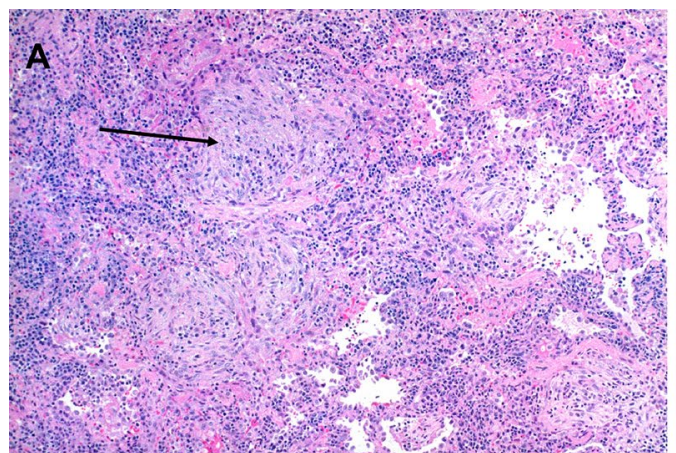

AIDs, as previously reported [52], whereas ACIF was only seen in HP [40]. However, the OP pattern was combined with UIP in some cases, and more important, LIP was present in several cases.
For several years, cryobiopsies are preferred over open lung biopsies in diagnosing fibrosing pneumonias. These biopsies are useful in all cases where a clinical and radiological diagnosis already favors IPF, AID, or HP, respectively. 
However, in those cases with unusual clinical and radiological patterns, a video-thoracoscopic biopsy is superior. The distribution of patterns as described above can be very focal, involving different lung segments or even lobes. This is also seen on CT scans, where honeycombing might be seen in one focus and ground-glass opacities in another. A larger piece of tissue will increase the likelihood of sampling all these different patterns.

\section{Conclusion}

We have shown that a pathological analysis can provide more than just IPAF diagnosis, which does not include fibrosing HP and encompasses acute disease. In our diagnostic workup, we should dig for the underlying etiology. In some cases, we might be able to discern AID from HP. This might provide additional clues for treatment. Even in those cases where the pathological report can only exclude IPF, this would enable clinicians to investigate additional treatment options. Although antifibrotic treatment is now recommended for any kind of UIP regardless of the underlying etiology, additional treatment options might be considered in cases of AID and HP.

In the authors' experience, a biopsy should be performed not only in cases where CT scan findings are inconclusive [53]. Lynch recommended a re-review of IPF cases on a regular basis, as the diagnosis might change. In our consultation praxis, we have seen cases initially diagnosed as IPF by CT scan and clinical presentation, which later turned into AID. A careful pathological analysis can provide much more information and might help clinicians stratify their patients early on. There are several limitations of our study. One is the small sample size, and another also is due to the retrospective analysis performed here. Despite these limitations, our study underlines the necessity for lung biopsies in AID and HP. In future studies, tissues analysis will enable us to uncover molecular drivers and modifiers of autoimmune diseases and possibly find new targets for treatment.

Supplementary Information The online version contains supplementary material available at https://doi.org/10.1007/s00296-021-05002-2.

Acknowledgements We would thank the many clinicians and pathologists from several hospitals for sending tissues and providing clinical diagnosis for second opinion diagnosis, tissues which have been used in this study.

Author contributions HP and ESP analyzed the cases and designed the study. LB analyzed part of the cases. AN provided several cases. HP wrote the draft manuscript, and all authors contributed to the final version.
Funding Open access funding provided by Medical University of Graz. No funding was received for this study.

Data availability All data have been included into the manuscript.

\section{Declarations}

Conflict of interest The authors declare no conflict of interest associated with this study.

Ethical approval The study was approved by the Ethical Committee of the Medical University of Graz (EK 24-135 ex 11/12).

Consent to participate A patient informed consent was not required as the patient data were anonymized.

Open Access This article is licensed under a Creative Commons Attribution 4.0 International License, which permits use, sharing, adaptation, distribution and reproduction in any medium or format, as long as you give appropriate credit to the original author(s) and the source, provide a link to the Creative Commons licence, and indicate if changes were made. The images or other third party material in this article are included in the article's Creative Commons licence, unless indicated otherwise in a credit line to the material. If material is not included in the article's Creative Commons licence and your intended use is not permitted by statutory regulation or exceeds the permitted use, you will need to obtain permission directly from the copyright holder. To view a copy of this licence, visit http://creativecommons.org/licenses/by/4.0/.

\section{References}

1. Vij R, Noth I, Strek ME (2011) Autoimmune-featured interstitial lung disease: a distinct entity. Chest 140:1292-1299. https://doi. org/10.1378/chest.10-2662

2. Alhamad EH, Cal JG, Alboukai AA, Shaik SA, Omair MA (2016) Autoimmune symptoms in idiopathic pulmonary fibrosis: clinical significance. Clin Respir J 10:350-358. https://doi.org/10.1111/ crj. 12224

3. Collins BF, Spiekerman CF, Shaw MA, Ho LA, Hayes J, Spada CA, Stamato CM, Raghu G (2017) Idiopathic interstitial pneumonia associated with autoantibodies: a large case series followed over 1 year. Chest 152:103-112. https://doi.org/10.1016/j.chest. 2017.03.004

4. Zhang-Hoover J, Stein-Streilein J (2004) Tolerogenic APC generate CD8+ T regulatory cells that modulate pulmonary interstitial fibrosis. J Immunol 172:178-185. https://doi.org/10.4049/jimmu nol.172.1.178

5. Zhang Y, Blattman JN, Kennedy NJ, Duong J, Nguyen T, Wang Y, Davis RJ, Greenberg PD, Flavell RA, Dong C (2004) Regulation of innate and adaptive immune responses by MAP kinase phosphatase 5. Nature 430:793-797. https://doi.org/10.1038/natur $\mathrm{e} 02764$

6. Sherer Y, Gorstein A, Fritzler MJ, Shoenfeld Y (2004) Autoantibody explosion in systemic lupus erythematosus: more than 100 different antibodies found in SLE patients. Semin Arthritis Rheum 34:501-537. https://doi.org/10.1016/j.semarthrit.2004.07.002

7. Bluestone JA, Bour-Jordan H, Cheng M, Anderson M (2015) T cells in the control of organ-specific autoimmunity. J Clin Invest 125:2250-2260. https://doi.org/10.1172/jci78089

8. Liang Y, Tsoi LC, Xing X, Beamer MA, Swindell WR, Sarkar MK, Berthier CC, Stuart PE, Harms PW, Nair RP et al (2017) A gene network regulated by the transcription factor VGLL3 as 
a promoter of sex-biased autoimmune diseases. Nat Immunol 18:152-160. https://doi.org/10.1038/ni.3643

9. Kono M, Nakamura Y, Yoshimura K, Enomoto Y, Oyama Y, Hozumi H, Enomoto N, Fujisawa T, Inui N, Hamada E et al (2016) Nonspecific interstitial pneumonia preceding diagnosis of collagen vascular disease. Respir Med 117:40-47. https://doi.org/ 10.1016/j.rmed.2016.05.030

10 Yousem SA, Gibson K, Kaminski N, Oddis CV, Ascherman DP (2010) The pulmonary histopathologic manifestations of the anti-Jo-1 tRNA synthetase syndrome. Mod Pathol 23:874-880. https://doi.org/10.1038/modpathol.2010.65

11. Romagnoli M, Nannini C, Piciucchi S, Girelli F, Gurioli C, Casoni G, Ravaglia C, Tomassetti S, Gurioli C, Gavelli G et al (2011) Idiopathic nonspecific interstitial pneumonia: an interstitial lung disease associated with autoimmune disorders? Eur Respir J 38:384-391. https://doi.org/10.1183/09031936.00094 910

12 Alhamad EH, Al-Kassimi FA, Alboukai AA, Raddaoui E, AlHajjaj MS, Hajjar W, Shaik SA (2012) Comparison of three groups of patients with usual interstitial pneumonia. Respir Med 106:1575-1585. https://doi.org/10.1016/j.rmed.2012.07.009

13. Solomon JJ, Brown KK (2012) Rheumatoid arthritis-associated interstitial lung disease. Open Access Rheumatol 4:21-31. https:// doi.org/10.2147/oarrr.S14723

14. Solomon JJ, Ryu JH, Tazelaar HD, Myers JL, Tuder R, Cool CD, Curran-Everett D, Fischer A, Swigris JJ, Brown KK (2013) Fibrosing interstitial pneumonia predicts survival in patients with rheumatoid arthritis-associated interstitial lung disease (RA-ILD). Respir Med 107:1247-1252. https://doi.org/10.1016/j.rmed.2013.05.002

15. Ferri C, Manfredi A, Sebastiani M, Colaci M, Giuggioli D, Vacchi C, Della Casa G, Cerri S, Torricelli P, Luppi F (2016) Interstitial pneumonia with autoimmune features and undifferentiated connective tissue disease: our interdisciplinary rheumatology-pneumology experience, and review of the literature. Autoimmun Rev 15:61-70. https://doi.org/10.1016/j.autrev.2015.09.003

16 Selman M, Pardo A (2014) Revealing the pathogenic and agingrelated mechanisms of the enigmatic idiopathic pulmonary fibrosis: an integral model. Am J Respir Crit Care Med 189:11611172. https://doi.org/10.1164/rccm.201312-2221PP

17 Chilosi M, Carloni A, Rossi A, Poletti V (2013) Premature lung aging and cellular senescence in the pathogenesis of idiopathic pulmonary fibrosis and COPD/emphysema. Transl Res 162:156173. https://doi.org/10.1016/j.trsl.2013.06.004

18. Álvarez D, Cárdenes N, Sellarés J, Bueno M, Corey C, Hanumanthu VS, Peng Y, D'Cunha H, Sembrat J, Nouraie M et al (2017) IPF lung fibroblasts have a senescent phenotype. Am J Physiol Lung Cell Mol Physiol 313:L1164-L1173. https://doi.org/10. 1152/ajplung.00220.2017

19. Gallob F, Brcic L, Eidenhammer S, Rumpp F, Nerlich A, Popper $\mathrm{H}$ (2020) Senescence and autophagy in usual interstitial pneumonia of different etiology. Virchows Arch. https://doi.org/10.1007/ s00428-020-02917-2

20. Diaz de Leon A, Cronkhite JT, Katzenstein AL, Godwin JD, Raghu G, Glazer CS, Rosenblatt RL, Girod CE, Garrity ER, Xing C, Garcia CK (2010) Telomere lengths, pulmonary fibrosis and telomerase (TERT) mutations. PLoS ONE. https://doi.org/10. 1371/journal.pone.0010680

21. Alder JK, Chen JJ, Lancaster L, Danoff S, Su SC, Cogan JD, Vulto I, Xie M, Qi X, Tuder RM et al (2008) Short telomeres are a risk factor for idiopathic pulmonary fibrosis. Proc Natl Acad Sci USA 105:13051-13056. https://doi.org/10.1073/pnas.0804280105

22. Tsakiri KD, Cronkhite JT, Kuan PJ, Xing C, Raghu G, Weissler JC, Rosenblatt RL, Shay JW, Garcia CK (2007) Adult-onset pulmonary fibrosis caused by mutations in telomerase. Proc Natl Acad Sci USA 104:7552-7557. https://doi.org/10.1073/pnas. 0701009104
23. Lawson WE, Grant SW, Ambrosini V, Womble KE, Dawson EP, Lane KB, Markin C, Renzoni E, Lympany P, Thomas AQ et al (2004) Genetic mutations in surfactant protein $C$ are a rare cause of sporadic cases of IPF. Thorax 59:977-980. https://doi.org/10. 1136/thx.2004.026336

24 Chibbar R, Shih F, Baga M, Torlakovic E, Ramlall K, Skomro R, Cockcroft DW, Lemire EG (2004) Nonspecific interstitial pneumonia and usual interstitial pneumonia with mutation in surfactant protein C in familial pulmonary fibrosis. Mod Pathol 17:973-980. https://doi.org/10.1038/modpathol.3800149

25. Wang Y, Kuan PJ, Xing C, Cronkhite JT, Torres F, Rosenblatt RL, DiMaio JM, Kinch LN, Grishin NV, Garcia CK (2009) Genetic defects in surfactant protein A2 are associated with pulmonary fibrosis and lung cancer. Am J Hum Genet 84:52-59. https://doi. org/10.1016/j.ajhg.2008.11.010

26. Peljto AL, Zhang Y, Fingerlin TE, Ma SF, Garcia JG, Richards TJ, Silveira LJ, Lindell KO, Steele MP, Loyd JE et al (2013) Association between the MUC5B promoter polymorphism and survival in patients with idiopathic pulmonary fibrosis. JAMA 309:2232-2239. https://doi.org/10.1001/jama.2013.5827

27. Borie R, Crestani B, Dieude P, Nunes H, Allanore Y, Kannengiesser C, Airo P, Matucci-Cerinic M, Wallaert B, Israel-Biet D et al (2013) The MUC5B variant is associated with idiopathic pulmonary fibrosis but not with systemic sclerosis interstitial lung disease in the European Caucasian population. PLoS ONE. https:// doi.org/10.1371/journal.pone.0070621

28 Evans CM, Fingerlin TE, Schwarz MI, Lynch D, Kurche J, Warg L, Yang IV, Schwartz DA (2016) Idiopathic pulmonary fibrosis: a genetic disease that involves mucociliary dysfunction of the peripheral airways. Physiol Rev 96:1567-1591. https://doi.org/ 10.1152/physrev.00004.2016

29. Fischer A, Antoniou KM, Brown KK, Cadranel J, Corte TJ, du Bois RM, Lee JS, Leslie KO, Lynch DA, Matteson EL et al (2015) An official European Respiratory Society/American Thoracic Society research statement: interstitial pneumonia with autoimmune features. Eur Respir J 46:976-987. https://doi.org/10.1183/ 13993003.00150-2015

30. Yoo H, Hino T, Han J, Franks TJ, Im Y, Hatabu H et al (2021) Connective tissue disease-related interstitial lung disease (CTDILD) and interstitial lung abnormality (ILA): evolving concept of CT findings, pathology and management. Eur J Radiol Open. https://doi.org/10.1016/j.ejro.2020.100311

31. Fischer A, Swigris JJ, Groshong SD, Cool CD, Sahin H, Lynch DA, Curran-Everett D, Gillis JZ, Meehan RT, Brown KK (2008) Clinically significant interstitial lung disease in limited scleroderma: histopathology, clinical features, and survival. Chest 134:601-605. https://doi.org/10.1378/chest.08-0053

32 Moua T, Zamora Martinez AC, Baqir M, Vassallo R, Limper AH, Ryu JH (2014) Predictors of diagnosis and survival in idiopathic pulmonary fibrosis and connective tissue disease-related usual interstitial pneumonia. Respir Res. https://doi.org/10.1186/ s12931-014-0154-6

33. Chung JH, Montner SM, Adegunsoye A, Lee C, Oldham JM, Husain AN, MacMahon H, Noth I, Vij R, Strek ME (2017) CT Findings, radiologic-pathologic correlation, and imaging predictors of survival for patients with interstitial pneumonia with autoimmune features. AJR Am J Roentgenol 208:1229-1236. https:// doi.org/10.2214/ajr.16.17121

34. Kim HC, Song JS, Park S, Yoon HY, Lim SY, Chae EJ et al (2020) Histologic features suggesting connective tissue disease in idiopathic pulmonary fibrosis. Sci Rep 10(1):21137

35 Leslie KO, Trahan S, Gruden J (2007) Pulmonary pathology of the rheumatic diseases. Semin Respir Crit Care Med 28:369-378. https://doi.org/10.1055/s-2007-985609

36 Kim HC, Lee JH, Chae EJ, Song JS, Song JW (2020) Longterm clinical course and outcome of interstitial pneumonia with 
autoimmune features. Respirology 25:636-643. https://doi.org/ 10.1111/resp. 13665

37 Chartrand S, Lee JS, Swigris JJ, Stanchev L, Fischer A (2019) Clinical characteristics and natural history of autoimmune forms of interstitial lung disease: a single-center experience. Lung 197:709-713. https://doi.org/10.1007/s00408-019-00276-7

38 Kamiya H, Panlaqui OM (2019) Systematic review and metaanalysis of the prognosis and prognostic factors of interstitial pneumonia with autoimmune features. BMJ Open. https://doi. org/10.1136/bmjopen-2019-031444

39. Hariri LP, Smith ML, Mino-Kenudson M, Allen TC, Attanoos R, Borczuk A, Burke L, Cagle PT, Capelozzi V, Dacic S et al (2020) Pulmonary pathology society perspective on the 2018 American Thoracic Society, European Respiratory Society, Japanese Respiratory Society, and Latin American Thoracic Society Idiopathic Pulmonary Fibrosis Clinical Practice Guidelines. Ann Am Thorac Soc 17:550-554. https://doi.org/10.1513/AnnalsATS. 201910-801PS

40 Churg A, Myers J, Suarez T, Gaxiola M, Estrada A, Mejia M, Selman M (2004) Airway-centered interstitial fibrosis: a distinct form of aggressive diffuse lung disease. Am J Surg Pathol 28:6268. https://doi.org/10.1097/00000478-200401000-00006

41. Raghu G, Remy-Jardin M, Myers JL, Richeldi L, Ryerson CJ, Lederer DJ, Behr J, Cottin V, Danoff SK, Morell F (2018) Diagnosis of idiopathic pulmonary fibrosis. an official ATS/ERS/JRS/ ALAT clinical practice guideline. Am J Respir Crit Care Med 198:e44-e68. https://doi.org/10.1164/rccm.201807-1255ST

42 Wright JL, Churg A, Hague CJ, Wong A, Ryerson CJ (2020) Pathologic separation of idiopathic pulmonary fibrosis from fibrotic hypersensitivity pneumonitis. Mod Pathol 33:616-625. https:// doi.org/10.1038/s41379-019-0389-3

43 Churg A (2020) Centrilobular fibrosis in fibrotic (Chronic) hypersensitivity pneumonitis, usual interstitial pneumonia, and connective tissue disease-associated interstitial lung disease. Arch Pathol Lab Med 144:1509-1516. https://doi.org/10.5858/arpa. 2019-0628-RA

44. Ito Y, Arita M, Kumagai S, Takei R, Noyama M, Tokioka F et al (2017) Serological and morphological prognostic factors in patients with interstitial pneumonia with autoimmune features. BMC Pulm Med 17(1):111
45. Kim HC, Lee JH, Chae EJ, Song JS, Song JW (2020) Long-term clinical course and outcome of interstitial pneumonia with autoimmune features. Respirology 25(6):636-643

46. Newton CA, Batra K, Torrealba J, Kozlitina J, Glazer CS, Aravena C, Meyer K, Raghu G, Collard HR, Garcia CK (2016) Telomererelated lung fibrosis is diagnostically heterogeneous but uniformly progressive. Eur Respir J 48:1710-1720. https://doi.org/10.1183/ 13993003.00308-2016

47 Xue M, Guo Z, Cai C, Sun B, Wang H (2019) Evaluation of the diagnostic efficacies of serological markers KL-6, SP-A, SP-D, CCL2, and CXCL13 in Idiopathic interstitial pneumonia. Respiration. https://doi.org/10.1159/000503689

48. Kelly BT, Moua T (2018) Overlap of interstitial pneumonia with autoimmune features with undifferentiated connective tissue disease and contribution of UIP to mortality. Respirology 23:600 605. https://doi.org/10.1111/resp.13254

49. Hancock WK, Barnett EV (1989) Demonstration of anti-idiotypic antibodies directed against IgM rheumatoid factor in the serum of rheumatoid arthritis patients. Clin Exp Immunol 75:25-29

50. Koopman WJ, Schrohenloher RE (1988) Rheumatoid factor diversity. In Vivo 2:73-77 (PMID: 2979820)

51 Papiris SA, Tsonis IA, Moutsopoulos HM (2007) Sjögren's syndrome. Semin Respir Crit Care Med 28:459-471. https://doi.org/ 10.1055/s-2007-985667

52. Nicholson AG, Colby TV, Wells AU (2002) Histopathological approach to patterns of interstitial pneumonia in patient with connective tissue disorders. Sarcoidosis Vasc Diffuse Lung Dis 19:10-17 (PMID: 12002379)

53 Lynch DA, Sverzellati N, Travis WD, Brown KK, Colby TV, Galvin JR, Goldin JG, Hansell DM, Inoue Y, Johkoh T et al (2018) Diagnostic criteria for idiopathic pulmonary fibrosis: a Fleischner Society white paper. Lancet Respir Med 6:138-153. https://doi. org/10.1016/s2213-2600(17)30433-2

Publisher's Note Springer Nature remains neutral with regard to jurisdictional claims in published maps and institutional affiliations. 